\title{
Origin and evolution of deep brain stimulation
}

\author{
Vittorio A. Sironi * \\ Research Institute on the History of Biomedical Thought, University of Milano Bicocca, Milan, Italy
}

Edited by:

Thomas E. Schlaepfer, University

Hospital of Bonn, Germany

Reviewed by:

Edward Shorter, University of Toronto, Canada

Patric Blomstedt, University Hospital of Umeå, Sweden

*Correspondence: e Chirurgia, Centro Studi sulla Storia del Pensiero Biomedico, Università di Milano Bicocca, Villa Serena, Via Pergolesi 33, 20900 Monza, MB, Italia.

e-mail: vittorio.sironi@unimib.it
Vittorio A. Sironi, Facoltà di Medicina

This paper briefly describes how the electrical stimulation, used since antiquity to modulate the nervous system, has been a fundamental tool of neurophysiologic investigation in the second half of the eighteenth century and was subsequently used by the early twentieth century, even for therapeutic purposes. In mid-twentieth century the advent of stereotactic procedures has allowed the drift from lesional to stimulating technique of deep nuclei of the brain for therapeutic purposes. In this way, deep brain stimulation (DBS) was born, that, over the last two decades, has led to positive results for the treatment of medically refractory Parkinson's disease, essential tremor, and dystonia. In recent years, the indications for therapeutic use of DBS have been extended to epilepsy, Tourette's syndrome, psychiatric diseases (depression, obsessive-compulsive disorder), some kinds of headache, eating disorders, and the minimally conscious state. The potentials of the DBS for therapeutic use are fascinating, but there are still many unresolved technical and ethical problems, concerning the identification of the targets for each disease, the selection of the patients and the evaluation of the results.

Keywords: deep brain stimulation, history, cerebral localization, neuronal devices, bioethics, stereotactic neurosurgery

\section{INTRODUCTION}

Since ancient times, electrical stimulation has been used to modulate the nervous system and to treat some neurological disorders (Rossi, 2003). Scribonius Largo, physician of the Roman emperor Claudius, in his text "Compositiones medicamentorum" (46 AD) suggested the application of electric ray (Torpedo torpedo and Torpedo nobiliana) on the cranial surface as a remedy for the headache. These fishes are known for being capable of producing an electric discharge and their scientific name comes from the Latin "torpere," to be stiffened or paralyzed (but also to be numb, insensitive), referring to the effect on someone who handles them (Debru, 2006). Electric fishes were later used for the treatment of seizures, depression, and pain until the eighteenth century (Kellaway, 1946; Schwalb and Hamani, 2008).

In the early ninetieth century Giovanni Aldini (1762-1834), nephew of the discoverer of animal electricity Luigi Galvani (17271798) and professor of Physics at the University of Bologna, performed electrical stimulations on the exposed human cerebral cortex of recently decapitated prisoners. In 1804, Aldini reported that cortical stimulation evoked horrible facial grimaces. This finding led him to conclude that the cortical surface could be electrically stimulated; supporting that electricity could have therapeutic effects in the treatment of many neuropsychiatric disorders (Aldini, 1804; Boling et al., 2002; Parent, 2004). Aldini's experimentations and hypotheses led to direct research into two strands that would later developed during the ninetieth and twentieth century: on the one hand the use of brain stimulation for neurophysiologic investigation (initially on animals and then on humans) to understand the functioning of the brain, on the other hand the use of the techniques of brain stimulation for therapeutic purposes.

\section{NEUROPHYSIOLOGIC BRAIN STIMULATION}

Concerning neurophysiologic research, in 1809 Luigi Rolando (1773-1831) first used galvanic current to stimulate the cortical cortex of animals (Rolando, 1809), highlighting the functions of brain areas, while in 1870 Gustav Fritsch (1838-1927) and Eduard Hitzing (1838-1907) showed that electrical stimulation of specific cortical areas evoked muscle contractions in dogs (Fritsch and Hitzing, 1870). In 1872 David Ferrier (1843-1924) identified monkey's cerebral cortex points whose stimulation was related to specific movements of the animal (Ferrier, 1873; Gross, 2007). In 1874 the American physician Robert Bartholow (1831-1904) was the first to report findings from studies of electrical stimulation of the cerebral cortex in an awake human (Bartholow, 1874). In 1882 the Italian neuropsychiatrist Ezio Sciamanna (1850-1905) performed a series of systematic experiments of electrical stimulation on a trepanned patient who had a traumatic brain injury (Sciamanna, 1882; Zago et al., 2008). In 1883 the Italo-Argentine surgeon Alberto Alberti (1856-1913) conducted an experiment lasting more than 8 months of cerebral stimulation in a woman in whom an eroding tumor of the skull allowed easy access to the dura mater surface, like in Bartholow's case (Alberti, 1886). Unfortunately, the contribution of these researches in determining the motor topography of the human brain nonetheless remained poorly exploited except to confirm the electrical excitability of the cortex and demonstrate the contralateral cortical hemispheric representation of motor functions (Zago et al., 2008).

More precise and systematic observations on the topography of the brain had been made in 1887 by the British surgeon Victor Horsley (1857-1916) (Vilensky and Gilman, 2002), but we should wait for until 1950 - when fundamental studies of the neurosurgeon Wilder Penfield (1891-1976) were published - before the 
brain stimulation of the human cortex could give a real accurate representation of the human brain functions, including motor and somatosensory areas (cortical homunculus; Penfield and Boldrey, 1937; Penfield and Rasmussen, 1950).

\section{THERAPEUTIC BRAIN STIMULATION}

Electroshock, introduced by Ugo Cerletti (1877-1963) in 1938 was the first modern example of therapeutic application of brain stimulation for the treatment of severe psychosis (Cerletti, 1940; Kalinowsky, 1986). The application of an electric current on the skull evoked an epileptic seizure that "roughly" remodeled the neural connections, providing a clinical improvement to the patients. Despite opposing opinions about this technique, this method had a more solid foundation rather than the dubious experiments of electrical brain stimulation for the treatment of schizophrenia and other mental illness conducted at Tulane University in the 1960 s (Baumeister, 2000).

Brain stimulation for pain control, used as early as 1950 with good effects through temporary electrodes implanted into brain regions, after a first experimental phase, found its explanation in the "gate control theory" developed by Melzach and Wall in 1962 (Rezai and Lozano, 2002). These previous studies were the basis that led to the development of new techniques of neurostimulation: transcranial magnetic stimulation, cortical brain stimulation, and deep brain stimulation (DBS).

Transcranial magnetic stimulation produces a magnetic field to modulate the excitability of the brain cortex. Unlike electroshock, it can stimulate only a specific area (selectivity) through an eight-shaped magnet and it does not involve loss of memory and/or seizures. It is mainly used for the treatment of psychiatric diseases, as obsessive-compulsive disorder and depression, and recently in one case of minimally conscious state (Wassermann et al., 2008; Piccione et al., 2011).

Cortical brain stimulation involves the application of chronic low-frequency electrical pulses on the motor cortex through intra- or extra-dural implantation of one or more electrodes connected to a generator with a battery located in the chest. It is particularly used for the treatment of some forms of Parkinson's disease, epilepsy, and dyskinesia, but also for the pain control and in patients afflicted with stroke (Pagni et al., 2005; Harvey and Nudo, 2007).

Deep brain stimulation is a surgical procedure that allows implanting microelectrodes precisely in some brain areas through a combination of stereotactic and neuroimaging techniques. A subcutaneous external pacemaker lets these electrodes send electrical impulses to the brain.

Deep brain stimulation is an evolution of functional stereotactic neurosurgery techniques, initially used to produce selective lesions of specific deep brain structures (thalamic and cerebellar nuclei). Thus, a new balance of damaged neural circuits could be found, removing the tremor in patients suffered from medically refractory Parkinson's disease and motor disorders of dyskinesias.

In 1947 Ernst Spiegel and Henry Wycis, modifying the original apparatus of Clarke and Horsley (1906), produced the first human stereotactic frame that using pneumoencephalogram allowed to determine Cartesian coordinates of structures around ventricles (basal ganglia) for identifying the precise localization of the targets that had to be destroyed by radiofrequency (Spiegel et al., 1947; Zonenshyn and Rezai, 2005). Intra-operative electrical stimulation of these structures was systematically used for the exploration and the localization of the deep cerebral nuclei and for confirming target (Guiot et al., 1961; Gildenberg, 2005). These observations led to suggest that these stimulations of deep cerebral nuclei could be used not only as a method for diagnostic purposes but also as a therapeutic method itself. Thus, the evolution from lesional to stimulating functional neurosurgery was determined (Porta and Sironi, 2009).

\section{DEEP BRAIN STIMULATION}

The origins of this technique are linked to the discovery of the effects of electrical stimulation of the deep brain areas, conducted during the stereotactic lesional functional neurosurgery to identify the correct position of coagulant electrodes for the treatment of dyskinetic disorders and tremor in Parkinson's disease (Schwalb and Hamani, 2008). Thanks to the spread of stereotactic method, various studies demonstrated that, while "low-frequency stimulation" $(5-10 \mathrm{~Hz})$ could enhance tremor and other correlated symptoms, "high-frequency stimulation" $(50-100 \mathrm{~Hz})$ resulted in a reduction of symptoms (Albe Fessard et al., 1963; Blomstedt and Hariz, 2010). The pioneers of DBS were Delgado et al. (1952), Bekthereva et al. (1963), Sem-Jacobsen (1965), and Cooper (1978). Deep electrical stimulation of brain structures was originally introduced as a therapeutic option to treat behavioral disorders or chronic pain.

In 1952, the Spanish neuroscientist José M. Delgado, basing on his experience of deep neurophysiologic electrical stimulation in animals, first described the technique of implantation of intracranial electrodes in humans, indicating the importance of this method for diagnosis and its possible therapeutic role in patients with mental disorders (Delgado et al., 1952). Over the next two decades, he implanted radio-equipped electrode arrays that he called "stimoceivers," in cats, monkeys, chimpanzees, gibbons, bulls, and even humans, and he showed that he could control subjects' mind and bodies with the push of a button. His experiments on animals were often very "theatrical." For example, in 1963 he demonstrated the possibility to stop a bull from charging in response to a radio-signal of one electrode implanted in the brain of animal. However, the critics contended that the stimulation did not quell the bull's aggressive instinct, as Delgado suggested, but rather forced it to turn to the left (Horgan, 2005).

At that time, he implanted electrodes in 25 human subjects, most of them schizophrenics and epileptics. In 1969 he described his brain stimulation researches and discussed critical aspects and ethic implications in the book Physical Control of the Mind: Toward a Psychocivilized Society, where he showed the tremendous opportunities but also the great risks derived from neurotechnology (Delgado, 1969).

The first to use chronic depth stimulation as a therapy in motor disorders was Natalia Petrovna Bekthereva, neuroscientist at the Institute of Experimental Medicine and the Academy of Medical Sciences in Leningrad. In 1963 she published a work on the use of multiple electrodes implanted in sub-cortical structures 
for the treatment of hyperkinetic disorders (Bekthereva et al., 1963). However, since her papers were written in Russian, her works were not well known around the world. In her "therapeutic electro-stimulation," as she named this method, she used "electric stimulation with high-rate pulses of suprathreshold current," achieving excellent results (Bekthereva et al., 1975).

The Norwegian neurophysiologist and psychiatrist Carl Wilhelm Sem-Jacobsen initially used depth electrodes implanted for recording and stimulation in patients with epilepsy and psychiatric disorders. He successfully implanted multiple electrodes in the thalamus to stimulate the targets in order to identify the best lesional site in Parkinson's disease. These electrodes were often left into the patient's brain for several months, without any side effects. As he wrote: "these electrodes could then be used, following stimulation responses, to make incremental staged lesions in the target area" (Sem-Jacobsen, 1965, 1966; Blomstedt and Hariz, 2010).

By the early 1970s, there were some reports of chronic DBS system implanted in the thalamus for the treatment of chronic pain (Hosobuchi et al., 1973; Mazars et al., 1974), and isolated experiences in the patients with persistent vegetative state (Hasserl et al., 1969; Sturm et al., 1979).

The experience of the American neurosurgeon Irving S. Cooper in placing electrodes over the cerebellum and into the deep thalamic nuclei for central palsy, spasticity and epilepsy was more extensive and continuous. In 1977 he reported its excellent results from chronic cerebellar stimulation in over 200 patients (Cooper, 1978).

The lack of correlation of opinion of efficacy between the patients and clinicians led Cooper and other scientists to perform double-blind studies on cerebellar stimulation for spasticity. The results of these studies did not try to show a real efficacy of this procedure (Schwalb and Hamani, 2008).

After the introduction of L-dopa in the late 1960s, there was a sharp decline of the surgical treatment of Parkinson's diseases and the ablative procedures continued, only targeting ventral intermediate nucleus (Vim) and globus pallidus. DBS progressed as a technique through its use in psychiatric and pain control surgery.

Despite the sharp decline of surgery for Parkinson's disease given the use of L-dopa, many groups continued to perform thalamotomy for tremor of various etiologies (Schwalb and Lozano, 2004). The positive effect of thalamic stimulation on tremor was well known (due to the diagnostic neurostimulation maneuver done prior to coagulation to be sure of being in the right target), but the idea to use chronic stimulation as a therapeutic method did not emerge until Benabid's preliminary report in 1987 on stimulation of the Vim nucleus (Benabid et al., 1987).

\section{PRESENT AND FUTURE OF DEEP BRAIN STIMULATION}

In 1991, both Benabid and Blond and Sigfried groups reported their results on thalamic DBSs for tremor (Benabid et al., 1991; Blond and Siegfrid, 1991). Subsequent studies found that the DBS of thalamus was safer than thalamotomy and especially bilateral thalamotomy. Likewise, the stimulation of globus pallidus was demonstrated safer than pallidotomy, originally proposed by Laitinen for medically refractory Parkinson's disease in the early 1990 s (Laitinen et al., 1992). The major safety of the DBS of these areas led a gradual abandonment of lesional techniques. In 1994 Pollak's group began to stimulate a new target, involved in Parkinson's disease: the sub-thalamic nucleus of Luys (STN; Pollak et al., 1993). In particular, the DBS of this area has been found to be effective for bradykinesia, tremor, and rigidity. Moreover, the stimulation of SNT and globus pallidus was explored for the treatment of both generalized and segmental dystonia (Yu and Neimat, 2008).

In addition to movement disorders, DBS was also mostly used and explored for treatment of chronic pain, subsequently approved by US Food and Drug Administration in 1989.

Concerning the future of DBS for movement disorders, although multiple studies demonstrated its efficacy, many questions still require answers. In deed, as above reported, DBS has been showed to be effective in patients with medically refractory Parkinson's disease in both motor function and quality of life, but it is unclear what the effect of these techniques are on nonmotor aspects of this pathology. Furthermore, we should exactly know when a patient could be considered as drug unresponsive and whether a early DBS could slow the progression of the disease. Concerning dystonia, a rigorous trial was conducted on the efficacy of DBS of globus pallidus for primary dystonia, but the report of DBS for secondary dystonia consists of small case series. On contrary, the efficacy of stimulation of SNT is still clearly defined for this disorder (Holloway et al., 2006; Benabid, 2007; Schwalb and Hamani, 2008).

BDS in the treatment of refractory epilepsy has gotten the attention from epileptologists due to its well-documented success in treating movement disorders. Early results of the SANTE trial should lay the foundation for widespread implementation of DBS for epilepsy targeting the anterior thalamic nucleus. Other hopeful target seems to be the caudate nucleus, the sub-thalamic nucleus, the cerebellum, the centro-median nucleus of the thalamus, and the hippocampus, even if the results are non-conclusive (Halpner et al., 2008; Lega et al., 2010).

Recently, the indication of the use of DBS has been extended to new diseases, so new interesting perspectives for future therapies seem to be opened. Bilateral thalamic stimulation has been used for the treatment of refractory Tourette syndrome, a complex pathology characterized by multiple motor tics and one or more phonic/vocal tics lasting longer than 1 year. The first results are positives with improved clinical features (Porta et al., 2010). DBS has been also indicated for the treatment of serious psychiatric disorders, such as refractory depression and obsessive-compulsive disorder. In addition to psychiatric diseases, DBS has also been suggested as a potential therapy for obesity, eating disorders, and drug resistant hypertension (Mayberg et al., 2005; Lipsman et al., 2007).

Although DBS for pain has been largely abandoned, the group of Milan has explored DBS of the posterior hypothalamus for cluster headache (Franzini et al., 2003; Leone et al., 2005). Moreover, a recent study has re-explored DBS for the minimally consciousness state after severe traumatic brain injury (Schiff et al., 2007).

\section{CONCLUSION}

Since the introduction of DBS, almost 20 years ago, there has been an immense resurgence of interest in the neurosurgical technique for the treatment of more neurological and psychiatric disorders. The reversible nature of stimulation technique is an 
attractive feature and clinical conditions that were not believed to be surgically tractable are now being considered suitable for DBS therapy.

The success of DBS in the treatment of refractory Parkinson disease is evident, while for the other motor disorders (primary tremor, dyskinesias, medically refractory Tourette's syndrome) good results are waited. The major psychiatric diseases (refractory depression, obsessive-compulsive disorder), cluster headache, epilepsy, eating disorders (obesity), and drug resistant hypertension are the new field where the DBS seems to have interesting therapeutic possibilities.

The potentials of this neurotechnique are fascinating, but many questions still remain unanswered. Several technical and ethical problems have to be still solved. What are the optimal targets for each disease? What other neurological and psychic disorders can DBS be applied to? What should be the criteria for selecting candidates? Only when they are or are considered as? For some diseases should DBS be used regardless of pharmacological therapy? Could an early use of DBS change the natural history of some kinds of disease? In addition, an objective and statistically valid assessment of long-term results and of possible technique-related complications is still central.

Ethical problems are not less important than clinical ones. In the selection of patients, it is fundamental to the involvement of

\section{REFERENCES}

Albe Fessard, D., Arfel, G., Guiot, G., Derome, P., Dela, H., Korn, H., Hertzog, E., Vourch, G., and Aleonard, P. (1963). Characteristic electric activities of some cerebral structures in man. Ann. Chir. 17, 1185-1214.

Alberti, A. (1886). Contribucion al studio de las localisationes cerebrales y a la patogénesis de la epilepsia. Buenos Aires: Biedma.

Aldini, J. (1804). Essai théorique et expérimental sur le galvanisme, avec une série d'expériences faites devant des commissaires de l'Institut nationale de France, et en divers amphithéâtres anatomiques de Londres. Paris: Fournier Fils.

Bartholow, R. (1874). Experimental investigations into the functions of the human brain. Am. J. Med. Sci. 134, 305-313.

Baumeister, A. A. (2000). The Tulane electrical brain stimulation program. A historical case study in medical ethics. J. Hist. Neurosci. 9, 262-278.

Bekthereva, N. P., Bondarchuck, A. N., Smirnov, V. M., Meliutcheva, L. A., and Shandurina, A. N. (1975). Method of electrostimulation of the deep brain structures in treatment of some chronic diseases. Confin. Neurol. 37, 136-140.

Bekthereva, N. P., Grachev, K. V., Orlova, A. N., and Iatsuk, S. L. (1963). Utilisation of multiple electrodes implanted in the subcortical structure of the human brain for the treatment of hyperkinesis. Zh. Nevropatol. Psikhiatr. Im. S S Korsakova 63, 3-8.

Benabid, A. L. (2007). What the future holds for deep brain stimulation. Expert Rev. Med. Devices 6, 895-903.

Benabid, A. L., Pollak, P., Gervason, C., Hoffmann, D., Gao, D. M., Hommel, M., Perret, J. E., and de Rougemont, J. (1991). Long-term suppression of tremor by chronic stimulation of the ventral intermediate thalamic nucleus. Lancet 337, 403-406.

Benabid, A. L., Pollak, P., Louveau, A., Henry, S., and de Rougemont, J. (1987). Combined (thalamotomy and stimulation) stereotactic surgery of the VIM thalamic nucleus for bilateral Parkinson's disease. Appl. Neurophysiol. 50, 344346.

Blomstedt, P., and Hariz, M. I. (2010). Deep brain stimulation for movement disorders before DBS for movement disorders. Parkinsonism Relat. Disord. 16, 429-433

Blond, S., and Siegfrid, J. (1991). Thalamic stimulation for the treatment of tremor and other movement disorders. Acta Neurochir. Suppl. 52, 109-111.

Boling, W., Olivier, A., and Fabinyi, G. (2002). Historical contributions to the modern understanding of

family members, in addition to their direct involvement with the informed consent. The procedure must be supported by interdisciplinary teams of neurosurgeons, neuroscientists, psychiatrist, psychologist, and other health professionals who can help assess patients' suitability for DBS and continuously monitoring them over time.

The DBS is not a modern form of psychosurgery and for this reason - technical and ethical - mistakes, that historically characterized this terrible chapter of history of neuroscience, should be avoided (Kringelbach and Aziz, 2010). While psychosurgery was a lesional unselective and irreversible manipulation of a brain area (e.g., the lobotomy proposed by Egas Moniz since 1935 and its subsequent variants), the primary goal of DBS is to rebalance the damaged neuronal circuits through a electrical selective and reversible manipulation (stimulation) of targeted brain structures, whose alteration may determine, along with neurological deficits, also behavioral problems (e.g., Tourette's syndrome). Concerning the "psychiatric" indications (refractory depression and obsessive-compulsive disorder), the evidences of organic alterations underlying these events provide an adequate explanation for the fact that the rebalancing of specific neurophysiologic substrates through the DBS can improve these behavioral disorders, harmonizing the physical and psychological expressions of these subjects.

function in the central area. Neurosurgery 50, 1296-1310.

Clarke, R. H., and Horsley, V. (1906). On a method of investigating the deep ganglia and tracts of the central nervous system (cerebellum). $\mathrm{Br}$. Med. J. 2, 1799-1800.

Cerletti, U. (1940). L'elettroshock. Riv. Sper. Freniatr. Med. Leg. Alien. Ment. I, 209-310.

Cooper, I. S. (1978). Cerebellar Stimulation in Man. New York: Raven Press.

Debru, A. (2006). The power of torpedo fish as a pathological model to the understanding of nervous transmission in antiquity. C. R. Seances Soc. Biol. Fil. 329, 298-302.

Delgado, J. (1969). Physical Control of the Mind. Toward a Psychocivilized Society. New York: Harper and Row.

Delgado, J., Hamlin, H., and Chapman, W. (1952). Technique of intracranial electrode implacement for recording and stimulation and its possible therapeutic value in psychotic patients. Confin. Neurol. 12, 315-319.

Ferrier, D. (1873). Experimental researches in cerebral physiology and pathology. West Riding Lunatic Asylum Med. Rep. 3, 30-96.

Franzini, A., Ferroli, P., and Leone, M., and Broggi, G. (2003). Stimulation of the posterior hypothalamus for treatment of chronic intractable cluster headaches: first reported series. Neurosurgery 52, 1095-1099; discussion 1099-1101.

Fritsch, G. T., and Hitzing, E. (1870). Über die elektrische Erregbarkeit des Grosshirns. Arch. Anat. Physiol. 37, 300-302.

Gildenberg, P. L. (2005). Evolution of neuromodulation. Stereotact. Funct. Neurosurg. 83, 71-79.

Gross, C. G. (2007). The discovery of motor cortex and ist background. $J$. Hist. Neurosci. 16, 320-321.

Guiot, G., Hardy, J., and Alabe-Fessard, D. (1961). Delimitation precise des structures sous-corticales et indentification de noyuax thalamiques chez l'homme par l'electrophysiologie stereotaxique. Neurochirurgia (Stuttg.) 5, 1-18.

Halpner, C. H., Samadani, U., Litt, B., Jaggi, J. L., and Baltuch, G. H. (2008). Deep brain stimulation for epilepsy. Neurotherapeutics 5, 59-67.

Harvey, R. L., and Nudo, R. J. (2007) Cortical brain stimulation: a potential therapeutic agent for upper limb motor recovery following stroke. Top. Stroke Rehabil. 14, 54-67.

Hasserl, R., Dalle Ore, G. D., Bricolo, A., Dieckmann, G., and Dolce, G. (1969). EEG and clinical arousal induced by bilateral longterm stimulation of pallidal systems in traumatic vigil coma. Electroencephalogr. Clin. Neurophysiol. 27, 689-690. 
Holloway, K. L., Baron, M. S., Brown, R., Cifu, D. X., Carne, W., and Ramakrishnan, V. (2006). Deep brain stimulation for dystonia: a meta-analysis. Neuromodulation 9, 253-261.

Horgan, J. (2005). The forgotten era of brain chips. Sci. Am. 293, 66-73.

Hosobuchi, Y., Adams, J. E., and Rutkin, B. (1973). Chronic thalamic stimulation for the control of facial anesthesia dolorosa. Arch. Neurol. 29, 158-161.

Kalinowsky, L. B. (1986). History of convulsive therapy. Ann. N. Y. Acad. Sci. 462, 1-4.

Kellaway, P. (1946). The part played by the electrical fish in the early history of bioelectricity and electrotherapy. Bull. Hist. Med. 20, 112-137.

Kringelbach, M. I., and Aziz, T. Z. (2010). Deep brain stimulation. Avoiding the errors of psychourgery. JAMA 301, 1705-1707.

Laitinen, L. V., Bergenheim, A. T., and Hariz, M. I. (1992). Leksell's posteroventral pallidotomy in the treatment of Parkinson's disease. J. Neurosurg. 76, 53-61.

Lega, B. C., Halpern, C. H., Jaggi, J. J., and Baltuch, G. H. (2010). Deep brain stimulation in the treatment of refractory epilepsy: update on current data and future directions. Neurobiol. Dis. 38, 354-360.

Leone, M., Franzini, A., Felisati, G., Mea, E., Curone, M., Tullo, V., Broggi, G., and Bussone, G. (2005). Deep brain stimulation and cluster headache. Neurol. Sci. 26(Suppl. 2), s138-s139.

Lipsman, N., Neimat, J. S., and Lozano, A. M. (2007). Deep brain stimulation for treatment-refractory obsessive-compulsive disorder: the search for a valid target. $\mathrm{Neu}$ rosurgery 61, 1-11; discussion 11-13.

Mayberg, H. S., Lozano, A. M., Voom, V., McNeely, H. E., Seminowicz, D., Hamani, C., Schwalb, J. M., and Kennedy, S. H. (2005). Deep brain stimulation for treatment-resistant depression. Neuron 45, 651-660.

Mazars, G., Merienne, L., and Cioloca, C. (1974). Traitement de certains types de doulers par des stimulateurs thalamiques implantes. Neurochirurgie 20, 117-124.

Pagni, C. A., Altibrandi, M. G., Bentivoglio, A., Caruso, G., Cioni, B., Fiorella, C., Insola, A., Lavano, A., Maina, R., Mazzone, P., Signorelli, C. D., Sturiale, C., Valzania, F., Zeme, S., and Zenga, F. (2005) Extradural motor cortex stimulation (EMCS) for Parkinson's disease. History and first results by the study group of the Italian neurosurgical society. Acta Neurochir. Suppl. 93B, 113-119.

Parent, A. (2004). Giovanni Aldini: from animal electricity to human brain stimulation. Can. J. Neurol. Sci. 31, 576-584.

Penfield, W., and Boldrey, E. (1937). Somatic motor and sensory representation in the cerebral cortex of man as studies by electrical stimulation. Brain 60, 389-443.

Penfield, W., and Rasmussen, T. (1950). The Cerebral Cortex of Man. A Clinical Study of Localisation of Function. New York: MacMillan.

Piccione, F., Cavinato, M., Manganotti, P., Formaggio, E., Storti, S. F., Battistin, L., Cagnin, A., Tonin, P., and Dam, M. (2011). Behavioral and neurophysiological effects of repetitive transcranial magnetic stimulation on the minimally conscious state: a case study. Neurorehabil. Neural Repair 25, 98-102.

Pollak, P., Benabid, A. L., Gross, C., Gao, D. M., Laurent, A., Benazzouz, A., Hoffmann, D., Gentil, M., and Perret, J. (1993). Effets de la stimulation du noyau sousthalamique dans la maladie de Parkinson. Rev. Neurol. 149, 175-176.

Porta, M., Brambilla, A., Capanna, A. E., Servello, D., Sassi, M., Rickards, H., and Robertson, M. M. (2010). Thalamic deep brain stimulation for treatment-refractory tourette syndrome. Two-year outcome. Neurology 73, 1375-1380.

Porta, M., and Sironi, V. A. (2009). Il cervello irriverente. Storia della malattia dei mille tic. Roma-Bari: Laterza, 136-143.

Rezai, A. R., and Lozano, A. M. (2002). "Deep brain stimulation for chronic pain," in Surgical Management of Pain, ed. K. J. Burchiel (New York: Thieme), 565-576.

Rolando, L. (1809). Saggio sopra la struttura del cervello dell'uomo e degli animali e sopra le funzioni del sistema nervoso. Sassari: Stamperia Privilegiata.

Rossi, U. (2003). “The history of electrical stimulation of the nervous system for the control of pain," in Electrical Stimulation and the Relief of Pain, ed. B. A. Simpson (Amsterdam: Elsevier B.V.), 5-16.

Schiff, N. D., Giacino, J. T., Klamar, K., Victor, J. D., Baker, K., Gerber, M., Fritz, B., Eisenberg, B., Biondi, T., O'Connor, J., Kobylarz, E. J., Farris, S., Machado, A., McCagg, C., Plum, F., Fins, J. J., and Rezai, A. R. (2007). Behavioural improvements with thalamic stimulation after severe traumatic brain injury. Nature 448, 600-6003.

Schwalb, J. M., and Hamani, C. (2008). The history and future of deep brain stimulation. Neurotherapeutics 5, 3-13.

Schwalb, J. M., and Lozano, A. M. (2004). Surgical management of tremor. Neurosurger. Q. 14, 60-68.

Sciamanna, E. (1882). Fenomeni prodotti dall'applicazione della corrente elettrica sulla dura madre e modificazione del polso cerebrale. Ricerche sperimentali sull'uomo. Atti della R. Accademia dei Lincei. Memorie della Classe di scienze Fisiche. Matematiche e Naturali 13, 25-42.

Sem-Jacobsen, C. W. (1965). Depth electrographic stimulation and treatment of patient with Parkinson's disease including neurosurgical technique. Acta Neurol. Scand. Suppl. 13, 365-377.

Sem-Jacobsen, C. W. (1966). Deptelectrographic observations relate to Parkinson's disease. Recording and electrical stimulation in the area around the third ventricle. $\mathrm{J}$. $\mathrm{Neu}$ rosurg. 24, 388-402.

Spiegel, E. A., Wycis, H. T., Marks, M., and Lee, A. S. (1947). Stereotactic apparatus for operation on the human brain. Science 106, 349-350.
Sturm, V., Kuhner, A., Schmitt, H. P., Assmus, H., and Stock, G. (1979), Chronic electrical stimulation of the thalamic unspecific activating system in a patient with coma due to midbrain and upper brain stem infarction. Acta Neurochir. 47, 235-244.

Vilensky, J. A., and Gilman, S. (2002). Horsley was the first to use electrical stimulation of the human cerebral cortex intraoperatively. Surg. Neurol. 58, 425-426.

Wassermann, E. M., Epstein, C. M., Ziemann, U., Walsh, V., Paus, T., and Lisanby, S. H. (2008). Oxford Handbook of $i$ Stimulation. New York: Oxford University Press.

Yu, H., and Neimat, I. S. (2008). The treatment of movement disorders by neural deep brain stimulation. Neurotherapeutics 5, 26-36.

Zago, S., Ferrucci, R., Fregni, F., and Priori, A. (2008). Bartholow, Sciamanna, Alberti: pioneers in the electrical stimulation of the exposed human cerebral cortex. Hist. Neurosci. 5, 521-528.

Zonenshyn, M., and Rezai, A. (2005). "Stereotactic surgery," in Principles of Neurosurgery, eds S. S. Rengachary and R. G. Ellenbogen (Edinburg: Elsevier), 785-817.

Conflict of Interest Statement: The author declares that the research was conducted in the absence of any commercial or financial relationships that could be construed as a potential conflict of interest.

Received: 26 January 2011; accepted: 02 August 2011; published online: 18 August 2011.

Citation: Sironi VA (2011) Origin and evolution of deep brain stimulation. Front. Integr. Neurosci. 5:42. doi: 10.3389/fnint.2011.00042

Copyright (ㄷ) 2011 Sironi. This is an openaccess article subject to a non-exclusive license between the authors and Frontiers Media SA, which permits use, distribution and reproduction in other forums, provided the original authors and source are credited and other Frontiers conditions are complied with. 